\title{
Revisión de los aspectos para la evaluación de la nutrición y alimentación en programas de salud de hato de ganado lechero I: evaluación del hato
}

\section{A review of the aspects for nutrition and feeding assessment in dairy cattle herd health programs I: herd assessment}

\section{Carlos Alpízar Solís ${ }^{1} \bowtie$, Juan José Romero²}

1* Sección de Nutrición Animal, Escuela de Medicina Veterinaria, Universidad Nacional, Costa Rica. carlos. alpizar.solis@una.cr

2 Programa de investigación en Medicina Poblacional, Escuela de Medicina Veterinaria, Universidad Nacional, Costa Rica.juan.romero.zuniga@una.cr

Recibido: 19 de julio de 2016. Corregido: 3 de marzo de 2017.Aceptado: 17 de marzo de 2017.

Resumen: La alimentación desempeña un rol preponderante en el rendimiento de las vacas lecheras y busca, fundamentalmente, llenar los requerimientos nutricionales de los animales, garantizar la salud y función digestivas, así como optimizar el aprovechamiento de los recursos disponibles y las raciones, para obtener la más óptima relación beneficio-costo por alimentación. Por tanto, las prácticas de alimentación empleadas deben orientarse a cumplir alguno o todos los aspectos anteriores. Esta revisión tiene como objetivo orientar sobre los principales aspectos de la alimentación del ganado bovino que deben considerarse, como mínimo, en los programas para la atención veterinaria de fincas dedicadas a la producción de leche bovina y apoyar las labores del veterinario. Además, busca la integración de diferentes aspectos médicos y de manejo, especialmente la alimentación y de esa manera, motivar a los veterinarios encargados de atender las fincas lecheras, a desarrollar y emplear las mejores herramientas o métodos de abordaje en las fincas. Se describen aspectos que se pueden medir y evaluar en la práctica, además de ser utilizados como referencia para el control de la alimentación, el estado nutricional, la salud ruminal, el desempeño de los animales y el balance de las raciones. Los aspectos de la nutrición y alimentación que se incluyen en el cuerpo del texto son el consumo de alimento, la condición corporal, el balance energético, la producción láctea, el metabolismo de nitrógeno y el funcionamiento y salud digestivas. Finalmente, se concluye que el manejo alimentario en la finca debe ir apoyado por el análisis integral de los datos obtenidos en la evaluación del sistema de alimentación, en conjunto con otros como la producción y reproducción; además, debe involucrarse a todo el equipo de trabajo en la evaluación de los resultados. Los esfuerzos deben orientarse a obtener las metas propuestas inicialmente para el sistema de alimentación.

Palabras clave: producción, leche, ganadería, sistemas de información, salud.

Autor para correspondencia.carlos.alpizar.solis@una.cr 


\begin{abstract}
Feeding plays a key role in dairy cows' performance and is mainly aimed at fulfilling their nutritional requirements, guaranteeing their digestive function and health, and optimizing use of available resources and feed rations, in order to obtain the most optimal feeding benefitprofit ratio. Therefore, feeding practices used should meet one or all of the previous objectives. The purpose of this review is to indicate the main aspects that should be considered at the very least regarding dairy cattle feeding in veterinary herd health programs for dairy farms and as support to the veterinary's work. In addition, different managing and medical aspects, especially regarding feeding, are integrated here to motivate veterinarians attending dairy farms to develop and use the best tools and methods for farms. Aspects that can be measured and evaluated in practice are also described and used as a reference to control feeding, the animals' nutritional status, ruminal health, performance and ration balancing. Nutrition and feeding aspects mentioned here include feed intake, body condition, energy balance, milk production, nitrogen metabolism and digestive function and health. Finally, it is concluded that feed managing in farms must be supported by an overall analysis of the data obtained through the feeding system assessment, together with other aspects such as production and reproduction; in addition, the entire work crew must be involved in the evaluation of results. Efforts must be directed towards reaching the goals initially proposed for the feeding system.
\end{abstract}

Keywords: production, milk, livestock, information systems, health.

\title{
Introducción
}

Actualmente, los médicos veterinarios, encargados de la atención de hatos lecheros, echan mano, cada vez más, de las ventajas que representan los programas de salud de hato, dado que la atención veterinaria de fincas lecheras se enfoca en la prevención de enfermedades y problemas relacionados con el manejo, así como en el control de la producción y de las operaciones diarias de la finca (Brand et al. 1996).

Fundamentalmente, la nutrición y la alimentación de las vacas lecheras en producción, garantizan el éxito de los programas de salud de hato. De igual manera, apoyan las prácticas de alimentación y la gestión del médico veterinario dentro de los sistemas de producción. Específicamente, la alimentación del ganado lechero tiene cuatro objetivos principales: llenar los requerimientos nutricionales de los animales, garantizar la función e integridad ruminal, optimizar el costo de las raciones y hacer un correcto uso de los recursos (Escobosa \& Ávila 2009). Esto permite que el correcto manejo de la alimentación del ganado lechero favorezca el equilibrio nutricional, principalmente el balance energético, proteico y mineral de la vaca durante el ciclo de producción, lo cual, involucra aspectos como: el consumo de materia seca, los mecanismos metabólicos involucrados en la obtención de energía, el manejo de productos nitrogenados, la dinámica y función ruminal, así como la calidad y composición de los ingredientes utilizados, además de su manejo y administración (NRC 2001).

Para ello, es indispensable saber y estimar los requerimientos nutricionales de los animales, conocer la composición nutricional de los ingredientes de la ración para lograr un correcto balance; reconocer las características físicas y químicas de los alimentos que ingiere el animal, los cuales influyen sobre muchas de sus funciones y procesos alimentarios y 
metabólicos, así como aquellos aspectos que se ven afectados por la dieta, de forma directa e indirecta, entre ellos, la función ruminal.

Asimismo, para garantizar que se cumplan los objetivos del sistema, se debe integrar, en un programa de salud de hato, la productividad de los animales y su relación con la salud digestiva, a través de la evaluación de la alimentación (Van Lier \& Regueiro 2008).

El objetivo de esta revisión consiste en describir los aspectos generales que debe considerar, como mínimo, un programa de salud de hato para la alimentación y nutrición de hatos bovinos lecheros. Cada aspecto incluye las variables por evaluar, algunos procedimientos prácticos y los puntos teóricos más relevantes que apoyan, en la práctica, los programas de salud de hato y control de la producción.

\section{Aspectos por considerar para la evaluación de la alimentación en ganado lechero}

A continuación, se describen los aspectos por tratar en este documento: la evaluación del consumo de alimento y agua, el monitoreo de la CC, la evaluación de la función digestiva, la evaluación de la producción y composición de la leche. Para cada aspecto, se incluyen objetivos generales de su evaluación, procedimientos y puntos clave por registrar e inspeccionar; por último, una revisión de aspectos teóricos implicados en cada caso.

\section{Evaluación del consumo de alimento y agua}

Según indica el Consejo Nacional de Investigación de los Estados Unidos de América (2001) (conocido como NRC por sus siglas en inglés), el consumo de alimento es uno de los aspectos de mayor importancia en los sistemas de alimentación, pues "establece la cantidad de nutrientes disponible para el animal para su salud y producción". Además, tanto la sub alimentación, como la sobre alimentación, tienen consecuencias negativas en el animal, en la finca y en el medio. Sin embargo, el agua es el nutriente más importante para el ganado lechero, pues participa en muchos procesos vitales. Sus pérdidas, a través de la respiración, evaporación, leche, orina y heces, son constantes, mientras su consumo depende del agua contenida en los alimentos, del agua metabólica y del agua de bebida. Además, el consumo de materia seca y de agua se relacionan estrechamente por lo cual, prestar atención a ambos aspectos es básico en la evaluación nutricional de los hatos.

De importancia notoria, es la estimación del consumo de materia seca, más que del alimento -tal como ofrecido-, aunque es difícil una estimación precisa del consumo debido a la gran cantidad de factores internos y externos al animal que pueden modificar esta variable. De igual manera, es vital estimar el consumo de agua de bebida en los animales, que corresponde aproximadamente al $83 \%$ del agua total consumida a diario (NRC 2001).

Más allá de pensar en los beneficios en el rendimiento productivo de las vacas por el consumo de materia seca y agua en la cantidad y calidad suficiente, ambos son aspectos fundamentales del bienestar animal, (Blokhuis et al. 2010) los cuales deben ser atendidos 
por los productores y vigilados por los médicos veterinarios.

\section{Objetivos}

- Optimizar el consumo de materia seca y agua durante el ciclo productivo.

- Obtener el máximo rendimiento productivo según la capacidad genética del hato.

- Disminuir la presentación de enfermedades en el período de transición.

- Apoyar el adecuado desempeño reproductivo del hato.

\section{Variables por registrar y evaluar}

\section{Consumo de materia seca}

La evaluación del consumo de materia seca (CMS) en ganado lechero se realiza de forma práctica, indirectamente, a través de la evaluación del llenado ruminal. Estas evaluaciones pueden realizarse diariamente, si es del interés del técnico y del productor, pero lo recomendable es adoptar una frecuencia semanal o, a lo sumo, quincenal. Siempre debe realizarse en el mismo momento del día, preferiblemente durante la tarde, pues durante el día las vacas consumen la mayor parte del alimento.

El desacato de estas recomendaciones, puede llevar a conclusiones erróneas debido a la variabilidad, en el consumo, en diferentes momentos del día.

Para evaluar el llenado ruminal, es necesario emplear un método que permita trabajar de forma práctica y sistemática, el cual debe realizarse en ausencia de contracciones obvias para evitar confusiones. Este método fue propuesto por Zaaijer \& Noordhuizen (2003), y está basado en la apreciación táctil y visual de los procesos transversos de las vértebras lumbares izquierdas o de la relación con la última costilla izquierda, y consta de puntuaciones con un rango entre 1 y 5 (Figura 1), tal como se detalla a continuación:

- Puntaje 1: la fosa paralumbar izquierda se hunde más del ancho de una mano, en relación con los procesos transversos de las vértebras lumbares. Indica un llenado mínimo.

- Puntaje 2: la fosa paralumbar izquierda se hunde menos del ancho de una mano, en relación con los procesos transversos de las vértebras lumbares. Indicativo de llenado deficiente, poco consumo, frecuente en los primeros días postparto.

- Puntaje 3: el saco ciego caudodorsal del rumen protruye, en la fosa paralumbar izquierda, aproximadamente una mano por debajo de los procesos transversos de las vértebras lumbares. Esta condición es deseable en vacas en lactancia inicial y media.

- Puntaje 4: el saco ciego caudodorsal del rumen sobresale inmediatamente debajo de los procesos transversos de las vértebras lumbares. Esta calificación es preferible para vacas en lactancia tardía. 


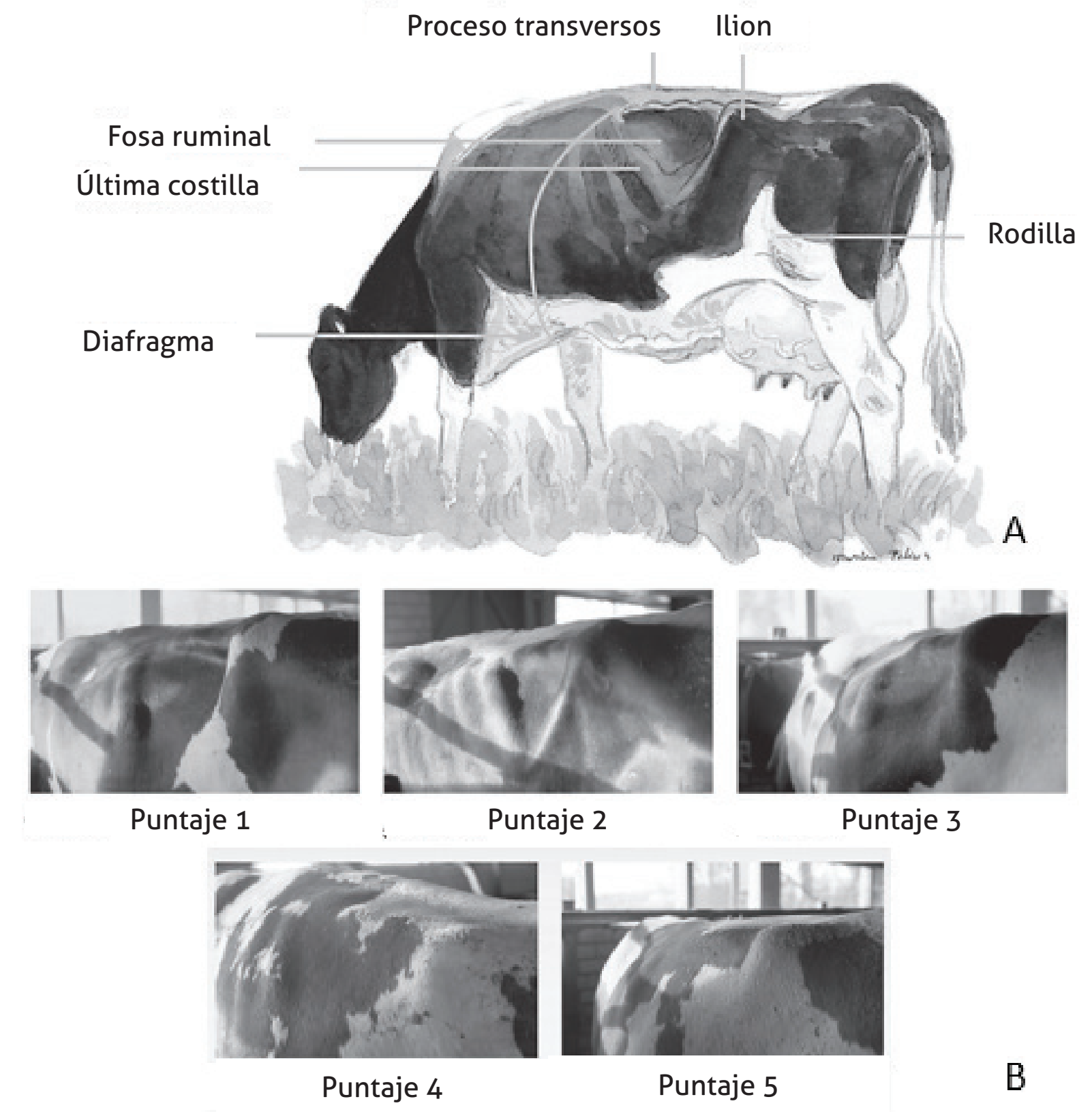

Figura 1. Esquema de puntos por identificar para estimar el grado de llenado ruminal (A) e imágenes que ilustran los cinco puntajes establecidos para este indicador (B). Fuente: Moran \& Doyle (2015).

- Puntaje 5: Los procesos transversos de las vértebras lumbares no son visibles. Esta es la calificación recomendada para las vacas secas. 
Una intervención puede ser necesaria cuando menos del $75 \%$ de las vacas, en una etapa de producción, no logra el llenado esperado (Hayton 2012). Los grupos que requieren de un control más regular del llenado ruminal y del CMS son las vacas en transición, en lactación temprana y las altas productoras.

\section{Consumo de agua}

El consumo de agua puede evaluarse semanalmente. Es posible la instalación de medidores de flujo de agua en las áreas destinadas para consumo (principalmente a la salida del ordeño) (Hayton 2012); sin embargo, es más importante garantizar el acceso y la calidad del agua para obtener un consumo adecuado. El monitoreo del consumo de agua puede presentar dificultades logísticas, las cuales pueden hacer que los resultados observados no tengan suficiente precisión; por tanto, es mejor garantizar suficiente espacio en los bebederos para que todos los animales tengan acceso al agua y esta sea de buena calidad. Esto evita mediciones incorrectas o errores de interpretación.

El acceso a fuentes de agua de calidad, con suficiente cantidad, es uno de los principales aspectos negativos encontrados en la evaluación del bienestar animal en fincas lecheras de Costa Rica (DiGiacinto et al. 2014), por lo cual, se está ante un problema que no es ajeno a la realidad de los sistemas de producción lechera local.

\section{Aspectos teóricos}

De manera general, el consumo de alimento está determinado a largo plazo por la producción láctea (NRC 2001); sin embargo, a mediano y corto plazo, el CMS depende del estado fisiológico de la vaca; así, cuando las vacas están en el período de transición, el CMS está regulado principalmente por la tasa de oxidación de propionato y lactacto, ácidos grasos y aminoácidos a nivel hepático, mientras que, durante el pico de lactancia, la regulación puede estar controlada por el llenado visceral (Allen \& Bradford 2008); a su vez, determinado por el contenido de fibra detergente neutra (FDN) (Van Soest \& Wine 1967; Dado \& Allen 1995; National Research Council 2001). Los mecanismos celulares involucrados en la regulación del CMS, en las vacas lecheras, posiblemente estén relacionados o sean similares a los descritos por Richards \& Proszkowiec-Weglraz (2007) en las especies monogástricas.

Es necesario considerar que existe un fuerte efecto de la cantidad de agua sobre el CMS, por lo cual, la disponibilidad de agua ad libitum y la estimulación de su consumo es de notable importancia para garantizar la ingesta de materia seca (NRC 2001). En este sentido, la verificación de la calidad química (nitratos, total de sales solubles y la dureza), física y microbiológica en el agua destinada al consumo del ganado lechero, también cobra una importancia significativa (National Research Council 1974).

La estimación del consumo de agua ha sido realizada por varios autores, cuyos resultados fueron retomados por Osborne (2006), quien sugiere un valor promedio de consumo de agua en vacas en producción de 4,6 litros por kilogramo de materia seca consumida, y de 2,6 litros 
por kilogramo de leche, aproximadamente. Es importante resaltar que, aproximadamente, el $22 \%$ del agua consumida por las vacas proviene de la humedad en el alimento, mientras que el restante $78 \%$ constituye el agua de bebida (Woodford et al. 1984; Holter \& Urba 1992). Muchos son los factores que afectan el consumo de agua en vacas lecheras, los cuales no son el objetivo de esta revisión, pero se recomienda al lector interesado referirse al trabajo de Murphy \& Davis (1983) para ampliar al respecto.

Maltz et al. (2013) observaron que el CMS también puede verse modificado, tanto por el tiempo empleado por los animales en comer, como por el tamaño de las diferentes comidas en el día, por lo cual, sería recomendable garantizar tiempo para el CMS de acuerdo con la frecuencia de alimentación, por ello, en términos generales, a menor frecuencia de alimentación, mayor tamaño de comidas y mayor tiempo por comida. En este sentido, para evaluar si el tiempo empleado es suficiente para lograr un CMS aceptable, se sugiere comparar el tiempo empleado por los animales en comer, usando como base el llenado ruminal.

Asimismo, determinar el consumo individual de ingredientes, como la FDN efectiva, es importante, pues puede determinar el consumo de materia seca diaria (Sheahan \& Kay 2013); además, es necesaria para garantizar la salud ruminal (Wattiaux \& Howard 2000). Por consiguiente, es necesario considerar la materia seca consumida proveniente del pasto y de los concentrados diariamente, en especial cuando se trata de salud digestiva; más aun, considerando el efecto sustitutivo que ejerce la suplementación con concentrados sobre el consumo de materia seca de pastos (Sheahan \& Kay 2013).

También, el CMS tiene un efecto importante sobre la actividad reproductiva. Por ejemplo, vacas con un balance energético negativo o con bajo CMS presentan un aumento en la concentración sanguínea de progesterona, que no es deseable en vacas que están listas para ser servidas. Este efecto puede atribuirse a la movilización de tejido graso para la obtención de energía o a la disminución del flujo sanguíneo a nivel hepático, lo que reduce el aclaramiento sanguíneo de la hormona, del mismo modo que hay ausencia del aumento de la FSH cuando existe un déficit de consumo y de energía (Ferraretto et al. 2014).

Finalmente, es necesario hacer énfasis en la evaluación constante del consumo de materia seca y de agua; pues, debido a su importancia, pueden considerarse la base del éxito del sistema de alimentación.

\section{Condición corporal}

La evaluación de la condición corporal (CC) de las vacas, a través de la apreciación visual y de la palpación de los depósitos grasos en sitios anatómicos predefinidos (Figura 2), tiene como objetivo conocer, de forma práctica, el balance energético de estos animales. En ello radica la importancia de su evaluación periódica, puesto que son bien conocidos los efectos perjudiciales de un balance energético negativo en el metabolismo, salud y la productividad de las vacas lecheras (Roche et al. 2009; Saborío \& Sánchez 2013). 


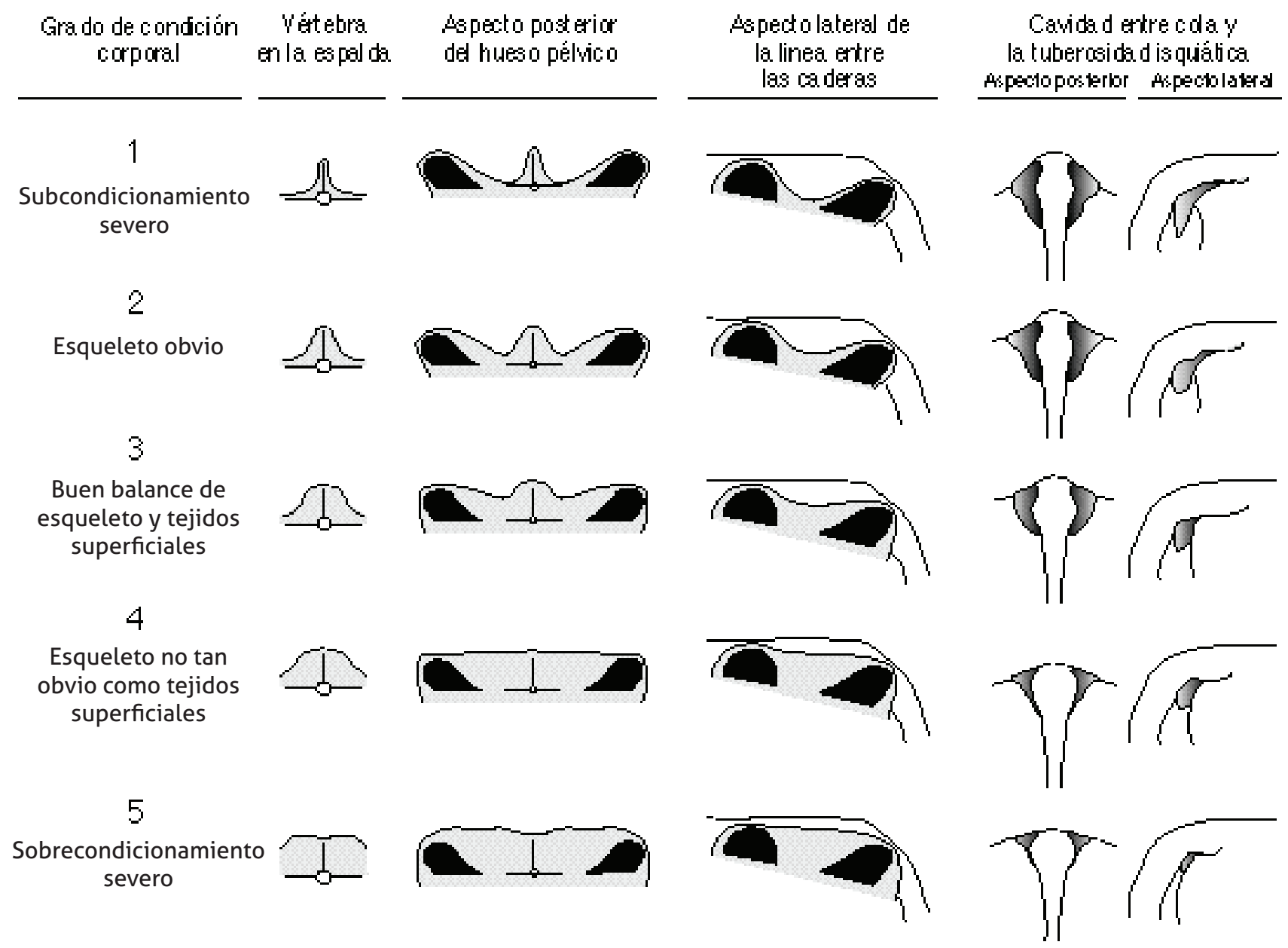

Figura 2. Esquema de calificación de la condición corporal en bovinos lecheros Holstein utilizando sitios anatómicos como referencia. Fuente: Edmonson (1989).

Del mismo modo que la CC que un animal presenta en un determinado momento de su lactancia es crítico, los cambios de este indicador, durante todo el ciclo de producción, requieren especial atención. Se estima que cada kilogramo de peso vacío de un animal con una condición corporal de 3 representa alrededor de 4,68 Mcal, y que cada punto de condición corporal representa, aproximadamente, un $13,7 \%$ del peso vivo (National Research Council 2001). Por tanto, un animal con un balance energético de $-1,2$ Mcal/día estaría perdiendo aproximadamente $0,25 \mathrm{~kg}$ de peso en el mismo período, lo cual representa $338 \mathrm{Mcal}$ para un animal de $550 \mathrm{~kg}$ de peso, que pasa de una condición corporal de 3,0 a 2,0 en aproximadamente 280 días. Esta energía proviene del catabolismo del tejido adiposo y muscular, lo cual refleja un balance energético negativo, que es un factor clave en la presentación de gran mayoría de enfermedades relacionadas con el déficit energético. Por 
tanto, cuanto más pronunciada es la disminución en condición corporal, menor balance energético y mayor el catabolismo de tejidos.

Estos procesos catabólicos son más significativos en animales con alta condición corporal $(>3,25)$ y con pérdidas de condición corporal superiores a 0,75 puntos en los primeros 60 días de lactancia, comparado con animales con menor o igual condición corporal y con menores pérdidas en el mismo período (Busato et al. 2002). Lo anterior, deja ver la importancia del correcto acondicionamiento y manejo energético de la vaca en todo su ciclo productivo.

\section{Objetivos}

- Evaluar el balance energético de las vacas durante el ciclo productivo.

- Ajustar la condición corporal a los rangos de referencia para las diferentes etapas del ciclo productivo.

- Evitar variaciones mayores a 1 punto en la condición corporal en las vacas durante el ciclo productivo.

\section{Aspectos por registrar y evaluar}

\section{Condición corporal}

El monitoreo de la condición corporal, en vacas en producción, puede realizarse de forma mensual, para todos los animales en el mismo período, si se trata de un sistema pequeño (menos de 100 vacas), o en un número aproximado a las 100 vacas en fincas más grandes (Hayton 2012); sin embargo, también es necesario considerar las facilidades de la finca para evaluar cierta cantidad de animales. Es necesario evaluar la CC de los animales al secado, al parto, en lactancia temprana y en lactancia media. Para lograr este objetivo, la evaluación de la CC se puede realizar cada vez que se haga el diagnóstico reproductivo por palpación rectal; así, se obtendría la CC en el posparto (30 días de lactancia), en las revisiones para declararlas listas para el servicio (45-60 días lactancia), al primer diagnóstico de gestación, en la revisión de los 4 meses de gestación, y al secado. Siendo así, el 100\% de las vacas en producción podrá ser evaluadas varias veces en un ciclo productivo, pudiendo observar sus cambios de manera sistemática. Según opinión de los autores, este es el abordaje más práctico para evaluar la CC del hato; sin embargo, queda a criterio del profesional la cantidad de animales evaluados y el momento de la evaluación, según las particularidades de cada establecimiento. Junto a esto, el registro sistemático de este indicador, especialmente utilizando un sistema de información automatizado, se convierte en una herramienta valiosa para su interpretación individual y poblacional. Por ejemplo, el sistema VAMPP Bovino (Nordhuizen \& Buurman 1984, Romero et al. 2011) permite registrar este indicador y analizar su dinámica en el hato (Figura 3).

Es recomendable que un número no mayor al $85 \%$ de los animales se encuentre por encima 
o por debajo del rango de condición corporal para la etapa del ciclo (Hayton 2012). Las calificaciones de CC meta pueden diferir entre razas pero, a manera de ejemplo, para vacas
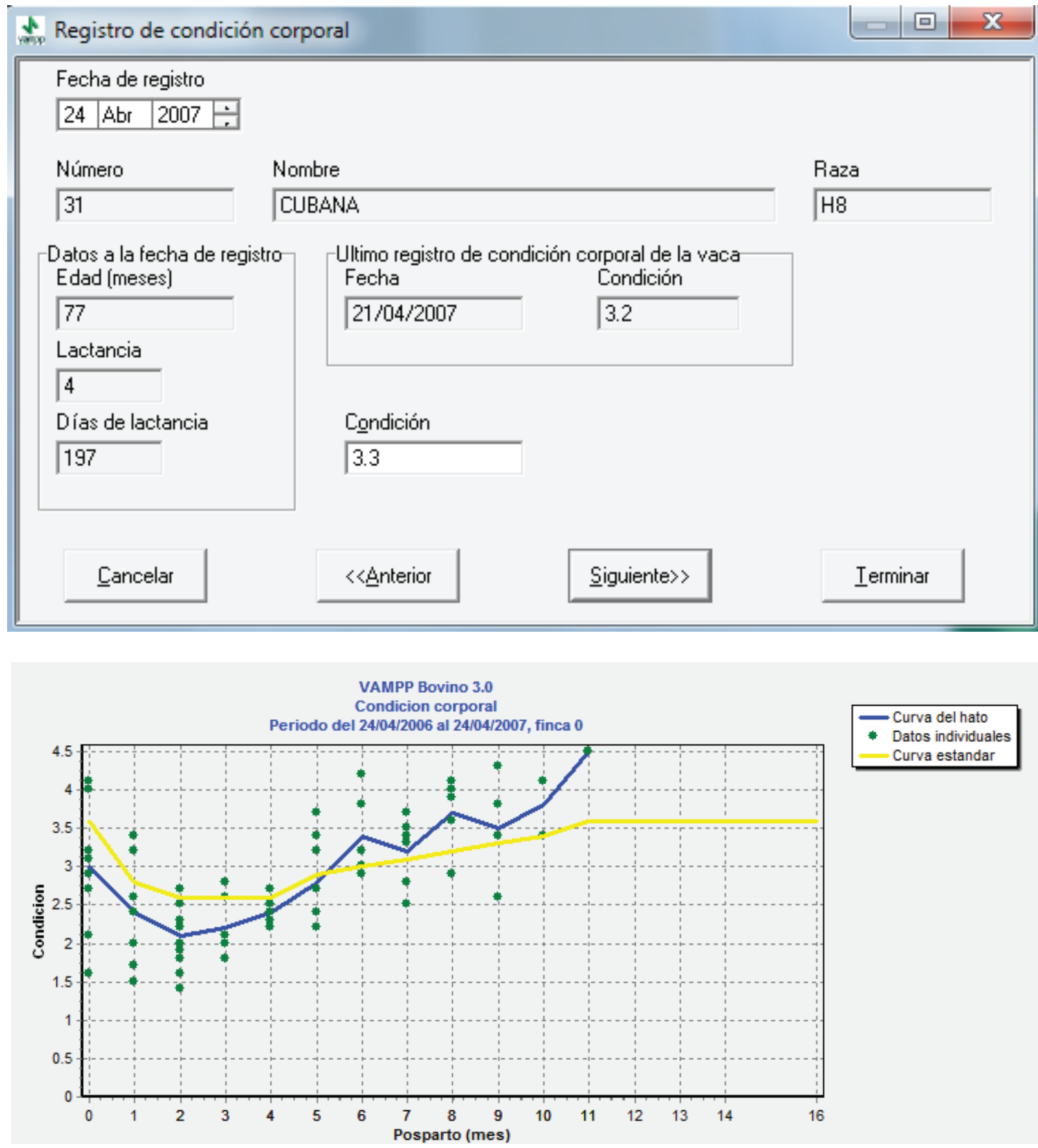

Figura 3. Pantalla de registro y gráfico colectivo de condición corporal en el programa informático VAMPP Bovino 3.0 . 
Cuadro 1. Valores de condición corporal ideales para vacas de raza Holstein Friesian. Fuente: Hayton 2012.

\begin{tabular}{|c|c|c|}
\hline Etapa & Calificación ideal & Rango \\
\hline Secado & 3 & $3,0-3,5$ \\
\hline Parto & 3 & $3,0-3,5(2,75-3,25$ novillas $)$ \\
\hline Lactación inicial & 2,5 & $2,5-3,0$ \\
\hline Lactación media & 2,75 & $2,5-3,0$ \\
\hline Lactación tardía & 3 & $2,75-3,25$ \\
\hline
\end{tabular}

de la raza Holstein el rango de CC meta durante el ciclo de producción se muestra en el Cuadro 1.

\section{Aspectos teóricos}

La evaluación de la CC no guarda una relación fija con el peso corporal de los animales (Berry et al. 2011), por consiguiente, no debe ser considerada como un método indirecto de pesaje. Asimismo, es necesario garantizar la consistencia y precisión de las evaluaciones de la condición corporal y reflejar, de la forma más precisa, los cambios en el estado energético de las vacas.

El efecto del estado nutricional, especialmente del balance energético y proteico, sobre el desempeño reproductivo de las vacas, es bien conocido (Butler 2000; Roche 2006). Este efecto tiene su explicación, en parte, en la naturaleza de los ingredientes de las raciones como sustratos energéticos y proteicos, así como de los procesos metabólicos ligados a estos sustratos que están involucrados en la regulación del estado energético y su interrelación con los procesos reproductivos (Van Knegsel et al. 2005).

Desde el punto de vista práctico, el peso corporal y la CC tienen una utilidad notable como indicadores del estado energético de los animales y son empleados en la evaluación y manejo de la reproducción de vacas lecheras (Randel 2013). Al respecto, la calificación de la CC antes y después del parto, así como el grado de pérdida de CC luego del parto, tienen una relación importante con la fertilidad (van Straten et al. 2009; Mulliniks et al. 2013), lo mismo que se ha reportado un efecto negativo de la movilización de grasas sobre la viabilidad y calidad de los embriones (Carvalho et al. 2014). Sin embargo, debido al efecto del manejo y la CC sobre la reproducción (Mulliniks et al. 2013); por tanto, es mejor la evaluación de la CC frecuentemente, en la medida de lo posible, en asociación con la medición del peso corporal y con el consumo de materia seca (Thorup et al. 2012).

\section{Funcionamiento digestivo}

\section{Objetivos}


- Evitar la presentación de alteraciones digestivas como: acidosis ruminal, desplazamiento de abomaso y diarreas.

- Evitar complicaciones secundarias a alteraciones del funcionamiento gastrointestinal.

\section{Aspectos por registrar y evaluar}

\section{Inspección de las heces}
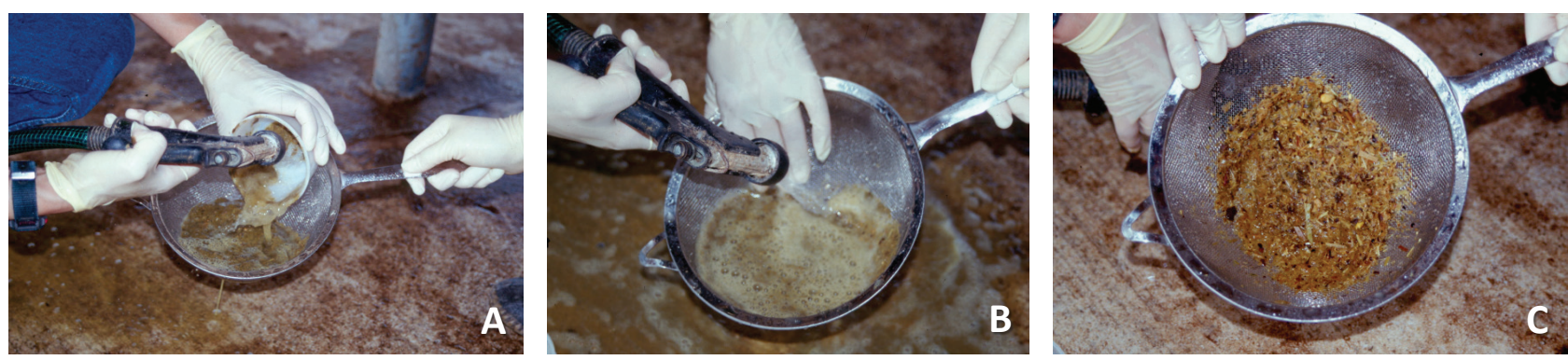

Figura 4. Inspección de las heces utilizando un tamiz y agua a presión para evaluar la cantidad, forma y grado de digestión de los alimentos. Fuente: Hall 2015.

La evaluación de las heces comprende la apreciación visual, in situ, del aspecto de las heces y su variación entre animales; pero, también debe incluir una inspección física, la cual incluye el lavado en un tamiz que permita apreciar la presencia y cantidad de granos no digeridos o parcialmente digeridos, el largo de las partículas fibrosas $(0,7$ a $1,25 \mathrm{~cm}), 0$ la presencia de grumos de muco (Figura 4).

La inspección de las heces se puede realizar cuando se visita la finca, o una semana posterior a un cambio importante en la alimentación; esto debido a la posibilidad de que las vacas tarden hasta
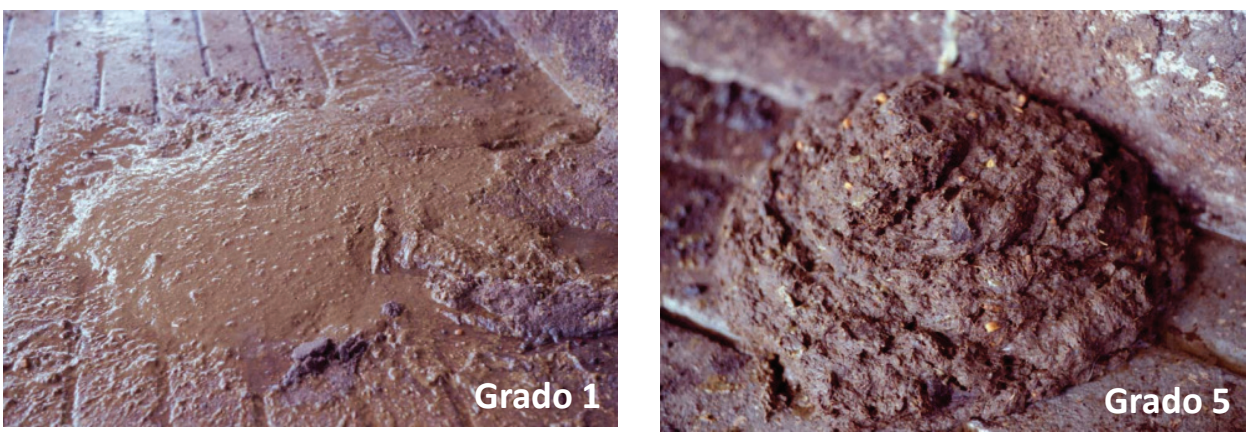

Figura 5. Ilustración de los grados extremos (1 y 5) de la consistencia de las heces de vacas lactantes. Fuente: Hall (2015). 
Cuadro 2. Criterios para la evaluación general de las heces de las vacas según su apariencia y consistencia. Fuente: Hall (2015).

\begin{tabular}{|c|c|c|}
\hline Grado & Apariencia & Factores Nutricionales \\
\hline \multirow[t]{2}{*}{1} & Líquido (como sopa de guisantes) & Mucha proteína o mucho almidón \\
\hline & Produce "charcos" y corre & $\begin{array}{l}\text { No suficiente fibra o consumo mineral } \\
\text { excesivo }\end{array}$ \\
\hline \multirow[t]{2}{*}{2} & Corre & Similares al número 1 \\
\hline & $\begin{array}{l}\text { Pilas }<2,4 \mathrm{~cm} \text { de alto Apariencia de } \\
\text { ondas o anillos }\end{array}$ & Consumo de pasto muy tierno \\
\hline \multirow[t]{2}{*}{3} & Consistencia de crema de afeitar & Ideal \\
\hline & $\begin{array}{l}\text { Pilas de casi } 4 \mathrm{~cm} \text { de } \\
\text { altura Anillos concéntricos } \\
\text { Hoyo en el centro }\end{array}$ & Ración balanceada \\
\hline \multirow[t]{3}{*}{4} & Grueso & Muy poca proteína o muy poco almidón \\
\hline & Pilas de más de $4 \mathrm{~cm}$ de altura & Mucha fibra en la ración \\
\hline & No hay huecos en el centro & Vacas secas o novillas \\
\hline 5 & Firme & $\begin{array}{l}\text { Dieta alta en forraje } \\
\text { Deshidratación }\end{array}$ \\
\hline
\end{tabular}

una semana en adaptarse a los nuevos cambios en su alimentación. El grupo de vacas, en transición y en lactación temprana, es el que requiere mayor atención. Una muestra de, aproximadamente, cinco animales por grupo suele ser suficiente por evaluación. Sin embargo, puede realizarse de forma sistemática, de manera rutinaria, al mismo momento en que se realiza la palpación rectal para el diagnóstico reproductivo. Se puede hacer visual, únicamente observando su apariencia en forma general, siguiendo los criterios que se presentan en el Cuadro 2 y se ilustran en la Figura 5.

Para efectos de practicidad, Kononoff et al. (2002) han descrito lo que llamaron las tres C de la observación de las heces, las cuales consisten en el color (normalmente desde un amarillo oliva hasta un verde oscuro, según la dieta); consistencia (similar a la avena remojada, en pilas concéntricas con forma de domo de hasta 5 centímetros de alto) y contenido (comprende los puntos descritos en el párrafo anterior) (Cuadro 2). Se espera que menos del $25 \%$ de las heces evaluadas presente alteraciones. Para un mayor detalle sobre las causas de posibles alteraciones en estas tres características, se refiere al lector al texto de Kononoff et al. (2002).

Es necesario recalcar que, aunque no existe literatura científica asociada directamente con las características de las heces con procesos específicos, su inspección es una herramienta muy útil para la evaluación de los sistemas de alimentación (Brand et al. 1996).

Conforme avanza la lactancia, el grado de calificación de las heces puede sufrir cambios considerados normales; así, las vacas en el posparto temprano pueden presentar 
consistencias entre 2,0 y 2,4; las de lactancia temprana, entre 1,4 y 3,0; en lactancia tardía, desde 3,0 a 3,4; finalmente, las secas, entre 3,0 y 4,0. Los grados 1 y 5 no son deseables en algún momento de la vida de los animales (Hall 2015).

\section{Inspección de la rumia}

El sistema digestivo de los rumiantes, gracias a la acción de ciertas enzimas microbiales, es capaz de degradar los carbohidratos estructurales de las paredes celulares vegetales (Herdt 2009); lo cual es crucial para la digestión de materiales fibrosos. Esto requiere del proceso de la rumia, que consiste, de forma general, en la remasticación de los alimentos ingeridos para facilitar la digestión bacteriana.

La inspección de la rumia se emplea como un indicador indirecto de la salud ruminal. Esta evaluación puede realizarse durante cada visita de rutina, preferiblemente siempre a la misma hora, debido a que el comportamiento de la rumia es variable durante el día. Se sugiere que, a manera de referencia, el $60 \%$ de los animales debería realizar la rumia mientras están en descanso, y en promedio deberían rumiar un bolo cada minuto.

Es más crítico evaluar el grupo de vacas que se encuentra en lactación temprana, en transición, y las altas productoras, debido a las características de la dieta y de la etapa productiva que son, en efecto, las que también deben ser evaluadas en CC y diagnóstico reproductivo, lo que facilita aprovechar los momentos de trabajo con estos grupos de animales.

\section{Inspección clínica de los animales}

En cada visita debe realizarse la inspección clínica de los animales con cualquier alteración relacionada con la función del sistema digestivo; tratar los animales que así lo requieran y hacer las intervenciones requeridas para corregir posibles desviaciones que estén afectando a los animales. Es necesario registrar todos los casos encontrados en cada visita, de manera que sea posible identificar patrones de presentación de alteraciones que permitan un análisis detallado y preciso de la situación de los problemas digestivos que ocurren en la finca. De la misma forma, es necesaria la inspección y registro de los animales sospechosos de presentar enfermedades metabólicas (por ejemplo hipocalcemia, hipomagnesemia y retención de membranas fetales).

A manera de referencia, es deseable la presentación de menos de un $5 \%$ de casos de fiebre de leche; menos del $5 \%$ de retención placentaria; menos del $3 \%$ de desplazamientos de abomaso para vacas con producciones de entre 8000 y 10000 litros por lactancia y de 7,5 a $10,0 \%$ de endometritis en animales con producciones similares. La frecuencia de la evaluación dependerá en gran medida a la incidencia del problema y del tamaño de las poblaciones expuestas (Hayton 2012). 


\section{Producción y composición láctea}

Uno de los objetivos principales de los sistemas de alimentación, en ganadería de leche, es obtener el mejor nivel posible de producción de los animales, según su capacidad genética (Samková et al. 2012), mejorar la eficiencia reproductiva de las vacas (Scandolo 2007) y mejorar las utilidades por unidad de área (Vibart et al. 2012), principalmente por la venta de la leche o sus derivados, de manera que se consiga un desempeño óptimo de los animales y la mayor rentabilidad.

No es el objetivo de este trabajo hacer una extensa revisión sobre el efecto de la dieta y la nutrición sobre la producción y la composición de la leche en bovinos, sino discutir la importancia del manejo nutricional en los programas de salud de hato para garantizar la productividad de las vacas, del sistema; y por tanto, la rentabilidad de la actividad.

\section{Objetivos}

- Obtener la máxima producción de leche según la capacidad genética de los animales.

- Garantizar la calidad láctea en lo referente al contenido de grasa y proteína.

- Garantizar la eficiencia del sistema de alimentación en términos de producción y calidad de la leche.

\section{Aspectos por registrar y evaluar}

\section{Producción láctea}

- Conversión alimenticia: la conversión alimenticia (CA), entendida esta como los kilogramos de alimento consumidos (materia seca) para producir un kilogramo de leche corregida al $4 \%$ de grasa, puede evaluarse quincenalmente, mensualmente, o cada vez que haya ajustes en la alimentación. Para ello, es necesario conocer el consumo de alimento y el promedio de producción de leche junto con la composición de la leche. La CA puede obtenerse al dividir el consumo de alimento (materia seca) entre los kilogramos de leche producida, corregida al $4 \%$. Este valor, a su vez, se puede calcular mediante la ecuación LC $4 \%=(0,4 \times$ Kg leche) $+(15 \times \%$ grasa en leche) (NRC 2001). Esta variable puede ser calculada para todos los grupos de vacas en producción, puesto que varía en función del momento de la curva de producción. Esta medición es útil como un indicador de eficiencia de las estrategias de alimentación (efecto de la formulación, selección en el consumo, por ejemplo), del desempeño de los animales, y como herramienta para la evaluación de los costos de alimentación (Hayton 2012).

- Curvas de producción: las curvas de producción pueden generarse de forma individual, 
por grupos o para todo el hato. Estas representan los picos de lactancia, la persistencia y la producción total por lactancia, datos que son muy útiles en la evaluación de la nutrición en lactación temprana. Por ejemplo, si el pico de lactancia se produce más allá de los 60 días postparto, se puede producir una prolongación del balance energético negativo. Es importante comparar las curvas de producción actuales con las curvas esperadas (o valores predichos), como una referencia para conocer la situación actual de la finca. Los sistemas informáticos, para el control de la producción, como VAMPP (Nordhuizen y Buurman 1984, Romero et al. 2011), permiten realizar este análisis, por lo cual, son una valiosa herramienta a la hora de realizar esta y otras tareas relacionadas, y

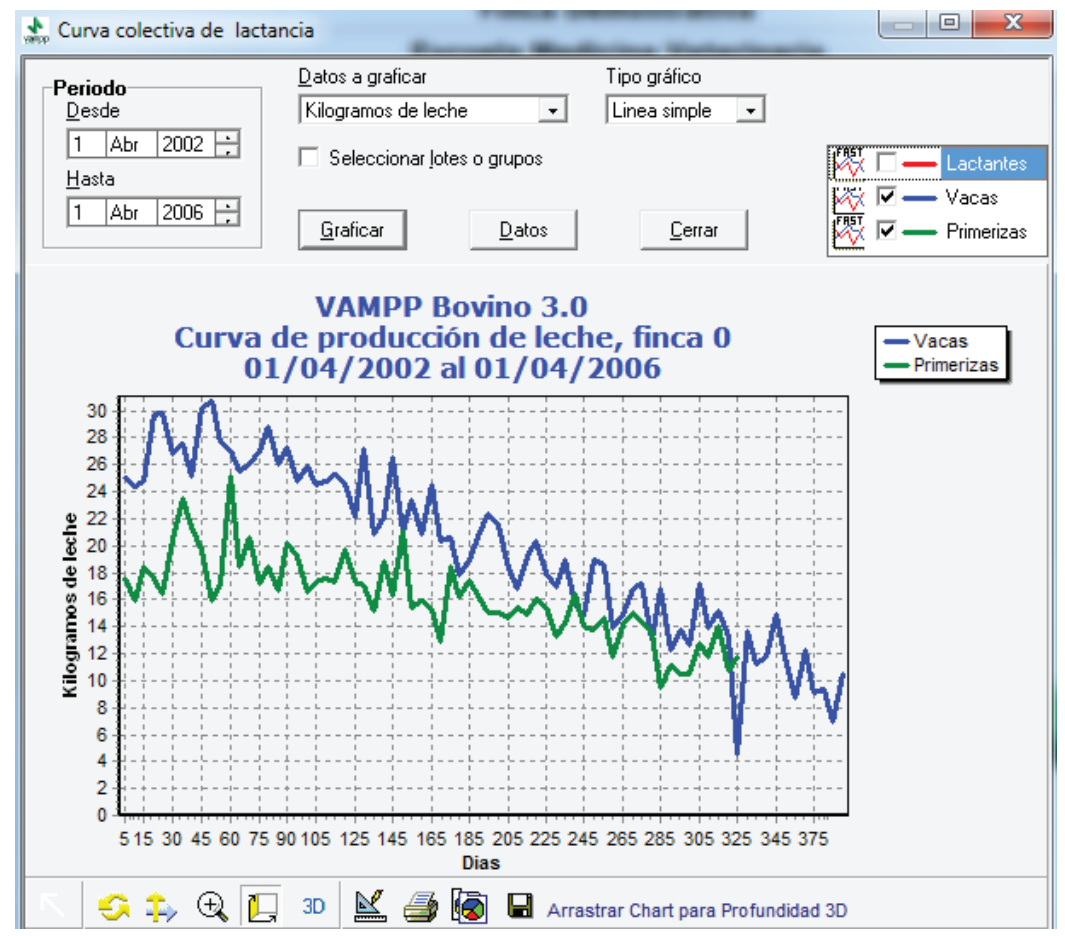

Figura 6. Curvas colectivas de producción de leche, generadas por el programa informático VAMPP Bovino, tanto para vacas como para primerizas.

constituyen una parte elemental del trabajo.

\section{Evaluación de la composición de la leche}

La evaluación de la composición de la leche implica dos aspectos de importancia para el sistema: 1) determina el ingreso por la venta y la calidad de la leche, y 2) puede indicar de forma indirecta la calidad y el efecto de la dieta que consumen los animales, en cuyo caso interesa mayormente el porcentaje de grasa en la leche, según se detalla en los "Aspectos teóricos". 
En el caso de la medición de la grasa en la leche, debido a la gran variabilidad en el porcentaje de grasa en vacas con menos de 100 días de lactancia, asociada a otros factores, más que con la alimentación (por ejemplo movilización de grasa corporal), lo correcto es realizarla, en forma mensual, en vacas con 100 o más días en lactancia. Es necesario establecer que, como mínimo, el $60 \%$ de los animales en el análisis debe mostrar un porcentaje de grasa en leche igual o superior al esperado para la condición específica de los animales y la finca, de lo contrario, puede ser necesario intervenir y detectar la causa de los resultados. De nuevo, el uso de sistemas informáticos automatizados donde se registre y analice estas variables, y su relación entre ellas, facilita, en mucho, el diagnóstico oportuno de problemas que afecten al hato (Figura 7).

Sin embargo, esta variable no se debe emplear como única referencia para tomar decisiones, debido a su carácter inespecífico como indicador de la condición nutricional de los animales. No obstante, se puede considerar la relación entre el contenido de grasa y proteína en la leche, evaluada individualmente de forma regular, para monitorear tanto la alimentación como la salud de las vacas. Se ha sugerido que relaciones grasa:proteína, con valores entre 1,2 y 1,4 se consideran normales. Sin embargo, valores menores a 1,1 ó mayores a 1.5 podrían indicar la presencia de acidosis ruminal o cetosis respectivamente (Cejna \& Chladek 2005),

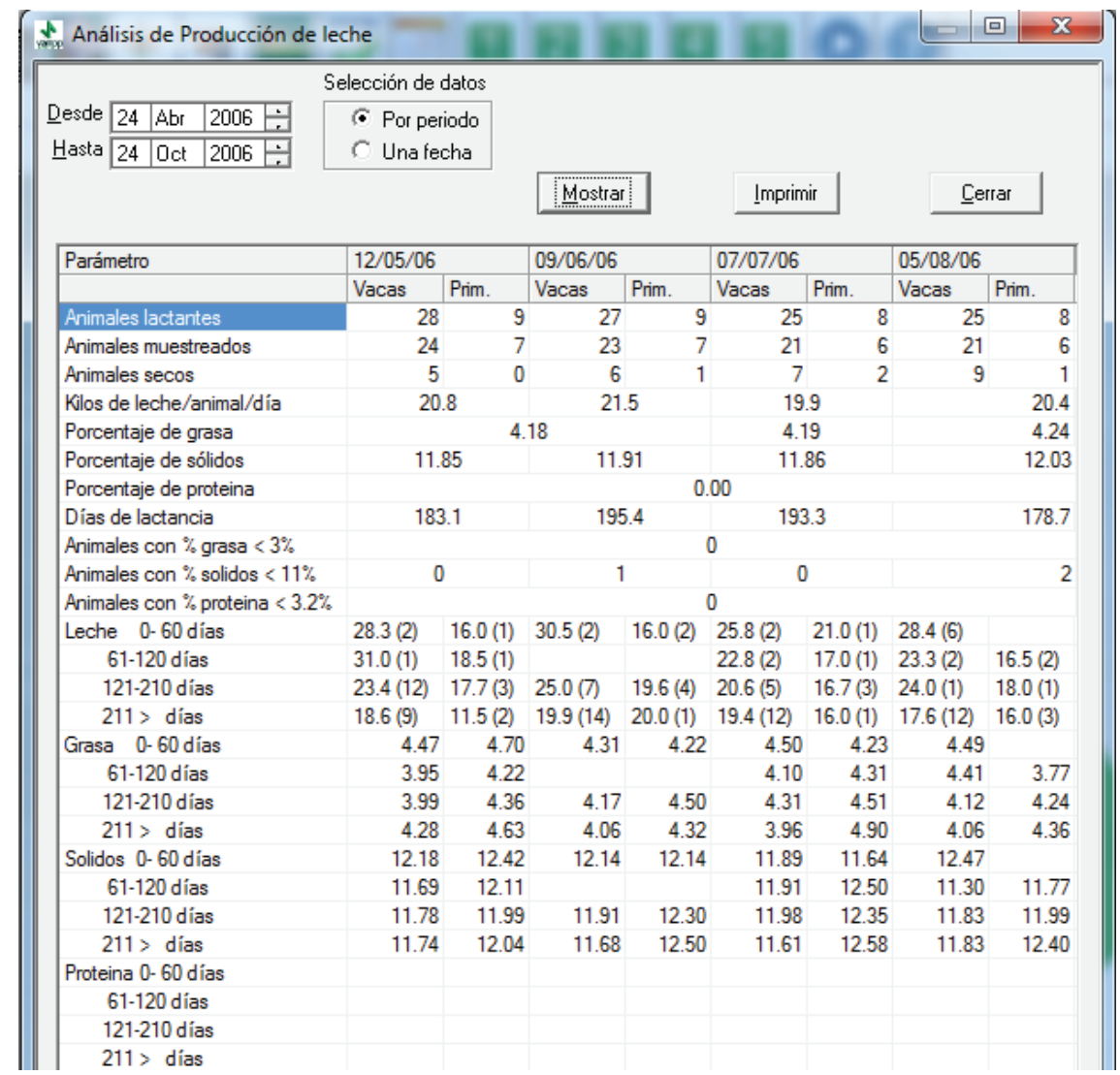

Figura 7. Ejemplo de un informe de calidad de leche, para una finca, por fechas de muestreo, generado por el programa VAMPP Bovino. 
ambas asociadas con importantes desajustes nutricionales y metabólicos. Pero no siempre se cumple esta condición, pues la dieta no es el único factor que influye en estos valores.

Además, mensualmente se puede analizar el contenido de nitrógeno ureico en leche; pues, como se discute más adelante, en "Aspectos teóricos", este valor puede ser un indicador del metabolismo del nitrógeno y del aporte y utilización de proteína en la dieta.

\section{Inspección clínica de los animales}

Para apoyar la producción láctea, es necesaria la inspección periódica de los animales, como una forma de procurar un óptimo estado de salud general para aprovechar su capacidad productiva. En este sentido, la evaluación de la rumia, del llenado ruminal, la calificación de las heces, así como de otros aspectos como la locomoción, la evaluación y control reproductivos y la salud de la ubre, son fundamentales para garantizar la salud y la producción. Los primeros 4 aspectos están relacionados (como ya se ha descrito) directamente con la alimentación de las vacas como herramientas para el monitoreo del consumo de materia seca y el funcionamiento gastrointestinal, y así ayudan en la evaluación de la alimentación, mientras que los dos últimos aspectos apoyan de forma directa la producción y la calidad de la leche y merecen una descripción de forma separada, la cual no está contemplada en los objetivos de este texto.

\section{Aspectos teóricos}

Es necesario considerar que, tanto el contenido de energía como de proteína de la dieta tienen un efecto importante sobre la producción y la composición de la leche. Se ha visto que un desbalance en la relación proteína/energía en la dieta de vacas lactantes (relación diferente a 17,4g/MJ EM, según el NRC 2001) puede asociarse a una disminución de la producción de sólidos no grasos como consecuencia de una disminución de proteínas y caseína (disminución del aporte de aminoácidos de la dieta a la glándula mamaria), así como de lactosa, lo que determina la presentación del efecto conocido como síndrome de la leche anormal o SILA (Ponce \& Hernández 2006).

Uno de los efectos más importantes de la dieta, sobre la composición láctea, es el que tiene sobre el porcentaje de grasa pues, de forma general, la FDN físicamente efectiva (estimado a través del producto entre la concentración de FDN en la dieta y la proporción de partículas mayores a 1,18 $\mathrm{mm}$ ) muestra una tendencia al aumento del porcentaje de grasa de la leche (Zebeli et al. 2008), gracias a una mayor producción y fermentación de acetato a nivel ruminal (Miyazawa et al. 2007).

Se ha descrito una importante relación entre el balance energético, la composición de la leche y de la grasa de la leche. Así, un balance energético negativo se asocia con el aumento del porcentaje de grasa en leche y el incremento de ácidos grasos saturados debido al traslado de las reservas de grasa corporal a la leche. Por otra parte, un consumo energético excesivo (por ejemplo, por alto consumo de concentrados) se asocia con una disminución del porcentaje de la grasa en leche, pero con un incremento de la concentración de ácidos grasos 
insaturados de cadena larga (C18:0 y C16:0). Esto último, se debe a una biohidrogenación incompleta de ácidos grasos a nivel ruminal (Stoop et al. 2009).

La interpretación de esta variable debe tomar en cuenta otros factores que pueden influir, como el efecto de la genética (Demeter et al. 2010), la etapa de lactancia (Stoop et al. 2009), la duración del período seco (van KVan Knegsel et al. 2014), la salud de la ubre (Malek dos Reis et al. 2013), y el número de partos (Nayak et al. 2012), por lo cual no debe considerarse el efecto aislado de cada uno en forma individual. Esto deja ver que la composición de la leche no es un indicador específico del estado nutricional, el cual debe ser analizado junto con otras variables que influyen significativamente en ella.

Otra variable que puede considerarse para la evaluación de la alimentación es el contenido de nitrógeno ureico en la leche (NUL) (Nousiainen et al. 2004). Scandolo (2007) refiere que valores de NUL, por debajo de los $7 \mathrm{mg} / \mathrm{dl}$, pueden reflejar un bajo contenido de proteína degradable en la dieta, mientras que una concentración superior a $19,6 \mathrm{mg} / \mathrm{dl}$ indicaría lo contrario. Sin embargo, Ishler (2008) sugiere que valores de MUN entre 8 y $14 \mathrm{mg} / \mathrm{dl}$ son aceptables, dependiendo de las características de la dieta utilizada, especialmente en cuanto a contenido de proteína y su balance con carbohidratos se refiere, y de la producción de leche. Por otra parte, el porcentaje de proteína en leche no tiene el mismo valor para la evaluación de la nutrición proteica y el metabolismo del nitrógeno que el NUL, aunque ambos compuestos sean nitrogenados, debido a que la fuente de proteína en la dieta parece no afectar significativamente el contenido proteína cruda de la leche (Aquino et al. 2008). Lo anterior, radica en que la síntesis de proteína en la glándula mamaria no está directamente ligada a la degradabilidad de la proteína en el rumen, la síntesis microbiana o la recirculación de urea (van Lier \& Regueiro 2008), sino al aporte local de aminoácidos (Ponce \& Hernández 2006; Bohuslav et al. 2013; Stahel et al. 2014).

El contenido de NUL puede verse afectado por muchas otras variables como etapa de lactancia, número de partos y temperatura ambiental (Fatehi \& Young 2012), efecto individual de hato y de vaca (Aguilar et al. 2012) y genética de los animales (Mucha \& Strandberg 2011), por lo que, nuevamente, su empleo en la toma de decisiones e intervenciones debe hacerse tomando las precauciones del caso.

Adicionalmente, se ha observado que el contenido de NUL está relacionado negativamente con el contenido de sal ( $\mathrm{NaCl}$ ) de la dieta (Spek et al. 2013), presumiblemente por un aumento de la filtración, a nivel glomerular, que puede aumentar la excreción de urea, debido a que a nivel renal es osmóticamente activa (Spek et al. 2012). Por esto, se debe prestar atención en los casos en los cuales las dietas pueden contener altas concentraciones de sodio, o en zonas en donde la concentración de sodio en agua de bebida tiene valores mayores a los sugeridos.

Finalmente, un hecho importante para garantizar la sostenibilidad de la actividad es que el monitoreo del NUL puede tener una importancia considerable respecto a la reducción del 
impacto ambiental de la ganadería de leche, especialmente en lo relativo a la disminución de las emisiones de amoniaco (Burgos et al. 2010; Powell et al. 2011).

\section{Conclusiones}

La evaluación periódica en el hato de variables como consumo de materia seca, CC, consumo de agua, producción y composición láctea, constituye un pilar fundamental en los programas de alimentación y nutrición; de ese modo, por la importancia de estos, sobre la salud y productividad de los animales, los programas de salud de hato para ganado lechero deben echar mano de protocolos de alimentación y nutrición. Además, es necesario el registro de esos indicadores, acompañado de una correcta interpretación de los resultados y datos obtenidos en las evaluaciones, de manera que apoyen, motiven y justifiquen la toma de decisiones en la finca.

Es posible incorporar los aspectos desarrollados en esta revisión en un protocolo de salud de hato y en las visitas mensuales a fincas sin que, necesariamente, signifique mayor trabajo y tiempo, pues de forma simultánea se pueden desarrollar tareas de observación y exploración de los animales, como por ejemplo: palpación rectal, evaluación de CC y llenado ruminal.

En síntesis, el éxito, en el desarrollo de programas de salud de hato, que incluyan la evaluación de la alimentación y nutrición, reside en realizar la recolección de datos y observaciones de forma eficiente pero precisa y complementarlo con su respectivo análisis de datos y toma de decisiones.

\section{Referencias}

Aguilar, M., Hanigan, M., Tucker, H., Jones, B., Garbade, S., McGilliard, M., Stallings, C., Knowlton, K. \& James, R. 2012. Cow and herd variation in milk urea nitrogen concentrations in lactating dairy cattle. Journal of Dairy Science. 95(12): 7261-7268. doi:10,3168/ jds,2012-5582.

Allen, M. \& Bradford, J. 2008. Nutritional control of feed intake in dairy cattle. In Florida Nutrition Conference. p. 138-148.

Aquino, A., Lima, Y., Botaro, B., Alberto, C., Peixoto, K. \& Santos, M. 2008. Effects of dietary urea levels on milk protein fractions of Holstein cows. Animal Feed Science and Technology. 140(1/2): 191-198. doi:10,1016/j.anifeedsci,2007,03,005.

Berry, D., Buckley, F. \& Dillon, P. 2011. Relationship between live weight and body condition score in Irish Holstein-Friesian dairy cows. Irish Journal of Agricultural and Food Research. 50(1): 141-147.

Bohuslav, Č., Martínková, L., Podkowka, Z., Lad, F., Šoch, M. \& Ingvortová, M. 2013. The Influence of Protein Feed Supplements for Composition of Cow Milk. Scientific Papers: Animal Science and Biotechnologies. 46(1): 23-26. 
Blokhuis, H., Veissier, I., Miele, M. \& Jones, B. 2010. The Welfare Quality Project and beyond: Safeguarding farm animal well-being. Acta Agric Scandinavica section A-Animal Science. 60(3): 129-140.

Brand, A., Noordhuizen, J. \& Schukken, Y. 1996. Herd Health and Production Management in Dairy Practice. Wageningen Press. Wageningen, Holanda. 543 pp.

Burgos, S., Embertson, N., Zhao, Y., Mitloehner, F., DePeters, E. \& Fadel, J. 2010. Prediction of ammonia emission from dairy cattle manure based on milk urea nitrogen: relation of milk urea nitrogen to ammonia emissions. Journal of Dairy Science. 93(6): 2377-86. doi:10,3168/jds,2009-2415.

Busato, A., Faissle, D., Küpfer, U. \& Blum, J. 2002. Body condition scores in dairy cows: associations with metabolic and endocrine changes in healthy dairy cows. Journal of Veterinary Medicine Association. 49: 455-460.

Butler, W.2000. Nutritionalinteractions with reproductive performancein dairycattle. Animal Reproduction Science. 60-61(1): 449-457. doi:10,1016/S0378-4320(00)00076-2.

Carvalho, P., Souza, A., Amundson, M., Hackbart, K., Fuenzalida, M., Herlihy, M., Ayres, H., Dresch, A., Vieira, L., Guenther, J., Grummer, R., Fricke, P., Shaver, R. \& Wiltbank, M. 2014. Relationships between fertility and postpartum changes in body condition and body weight in lactating dairy cows. Journal of Dairy Science. 97(6): 3666-3683. doi:10,3168/jds,2013-7809.

Cejna, V. \& Chladek, G. 2005. The importance of monitoring in milk fat to milk protein ratio in holstein cows during lactation. Journal of Central European Agriculture. 6(4): 539-546.

Herdt, T. 2009. Fisiología y metabolismo gastrointestinal. In: Klein, B. (Ed.). Cunningham: Fisiología Veterinaria. $4^{\mathrm{a}}$ Edición. Elsevier. Madrid, España. p. 280-302.

Dado, R. \& Allen, M. 1995. Intake limitations, feeding behavior, and rumen function of cows challenged with rumen fill from dietary fiber of inhert bulk. Journal of Dairy Science. 78(1): 118-113. doi:10,3168/jds.S0022-0302(95)76622-X.

Demeter, R., Markiewicz, K., van Arendonk, J. \& Bovenhuis, H. 2010. Relationships between milk protein composition, milk protein variants, and cow fertility traits in Dutch Holstein-Friesian cattle. Journal of Dairy Science. 93(11): 5495-5502. doi:10,3168/ jds,2010-3525.

DiGiacinto, A., Rojas, M., Estrada, S. \& Romero, J. 2014. Bienestar animal en hatos lecheros especializados de Costa Rica asociados a una cooperativa de productores de leche. Revista Ciencias Veterinarias. 32(1): 7-19.

Edmonson, J., Lean, I., Weaver L., Farver, T. \& Webster, G. 1989. A body condition scoring chart for Holstein dairy cows. Journal of Dairy Science. 72(1): 68-78. doi: 10,3168/jds. S0022-0302(89)79081-0.

Escobosa, A. \& Ávila, S. 2009. Alimentación. In: Avila, S. (Ed.). Producción de leche con

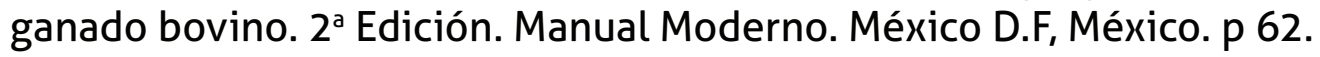


Fatehi, F. \& Young, J. 2012. Review of the relationship between milk urea nitrogen and days in milk, parity, and monthly temperature mean in Iranian Holstein cows. Journal of Dairy Science. 95(9): 5156-5163. doi: 10,3168/jds,2011-4349.

Ferraretto, L., Gencoglu, H., Hackbart, K., Nascimento, A., Dalla-Costa, F., Bender, R., Guenther, J., Shaver, R. \& Wiltbank, M. 2014. Effect of feed restriction on reproductive and metabolic hormones in dairy cows. Journal of Dairy Science. 97(2): 754-763. doi:10,3168/jds,2013-6925.

Hall, M. 2015. Using manure Evaluation as a Diagnostic Tool for Feedng Programs. U.S Dairy Forage Research Center USDA-Agrucultural Research Service. Madison, Wi. http:// www.ars.usda.gov/sp2UserFiles/Place/36553000/px-based_v3,2/educ-matrls/pdfs/ PP_manure-evaluation_hall.pdf (accesado 23 noviembre 2015).

Hayton, A. 2012. Nutritional Management of Herd Health. En Green, M. (Ed.). Dairy Herd Health. CABI. Oxfordshire, Inglaterra. p. 227-278.

Holter, J. \& Urba, W. 1992. Water Partitioning and intake in dry and lactating Holstein Cows. Journal of dairy science. 75(1): 1742-1749.

Ishler, V. 2008. Interpretation of milkurea nitrogen values. http://extension.psu.edu/animals/ dairy/nutrient-management/certified-dairy/tools/interpret-mun-values-08134.pdf. (Accesado 22 enero 2016).

Kononoff, P., Heinrichs, J. \& Varga, G. 2002. Using Manure Evaluation to enhance dairy cattle nutrition. http://www.vetmed.wsu.edu/courses-jmgay/documents/manure1.pdf. (Accesado 12 mayo 2015).

Malek dos Reis, C., Barreiro, J., Mestieri, L., Porcionato, M. \& dos Santos, M. 2013. Effect of somatic cell count and mastitis pathogens on milk composition in Gyr cows. BMC Veterinary Research. 9(1): 67. doi:10,1186/1746-6148-9-67.

Maltz, E., Barbosa, L., Bueno, P., Scagion, L., Kaniyamattam, K., Greco, L., De Vries, A. \& Santos, J. 2013. Effect of feeding according to energy balance on performance, nutrient excretion, and feeding behavior of early lactation dairy cows. Journal of Dairy Science. 96(8): 5249-5266. doi:10,3168/jds,2013-6549.

Miyazawa, K., Sultana, H., Hirata, T., Kanda, S. \& Itabashi, H. 2007. Effect of brewer's grain on rumen fermentation, milk production and milk composition in lactating dairy cows. Animal Science Journal. 78(5): 519-526. doi:10,1111/j,1740-0929,2007,00471.x.

Moran, J. \& Doyle, R. 2015. Cow talk: Understanding Dairy Cow Behaviour to Improve Their Welfare on Asian Farms. CSIRO Publishing. Charles Sturt University. 256 pp.

Mucha, S. \& Strandberg, E. 2011. Genetic analysis of milk urea nitrogen and relationships with yield and fertility across lactation. Journal of Dairy Science. 94(11): 5665-5672. doi:10,3168/jds,2010-3916.

Mulliniks, J., Cox, S., Kemp, M., Endecott, R., Waterman, R., Vanleeuwen, D. \& Petersen, 
M. 2013. Relationship between body condition score at calving and reproductive performance in young postpartum cows grazing native range 1. Journal of animal science. 90(1): 2811-2817. doi:10,2527/jas2011-4189.

Murphy, M. \& Davis, C. 1983. Factors affecting water consumption by Holstein cows in early lactation. Journal of Dairy Science. 66(1): 35-38.

National Research Council. 1974. Nutrients and Toxic Substances in Water for Livestock and Poultry. National Academy Press. Washington D.C.

National Research Council. 2001. Nutrient Requierements of Dairy Cattle, $7^{a}$ Edición. National Academy Press. Washington D.C.

Nayak, K., Kurrey, S. \& Nanavati, N. 2012. Factors Affecting Milk Composition of Frieswal Cows. Indian Journal of Field Veterinarians. 7(3): 56-58.

Noordhuizen J. \& Buurman., J.1984. Veterinary automated management and production control program for dairy farms (VAMPP). The application of MUMPS for data processing. Vet 0. 6(2): 66-72.

Nousiainen, J., Shingfield, K. \& Huhtanen, P. 2004. Evaluation of milk urea nitrogen as a diagnostic of protein feeding. Journal of Dairy Science. 87: 386-398. doi:10,3168/jds. S0022-0302(04)73178-1.

Osborne, V.R. 2006. Water: The Forgotten Nutrient Background on Water "The Mega Molecule". WCDS Advances in Dairy Technology. 18(1): 197-210.

Ponce, R. \& Hernández, P. 2006. Relación entre desbalances nutricionales, el metabolismo y la composición de la leche en vacas holstein friesian. Revista Salud Animal. 28(1): 13-20.

Powell, J., Wattiaux, M. \& Broderick, G. 2011. Short communication: Evaluation of milk urea nitrogen as a management tool to reduce ammonia emissions from dairy farms. Journal of Dairy Science. 94(9): 4690-4694. doi:10,3168/jds,2011-4476.

Randel, R. 2013. Nutrition and postpartum rebreeding in cattle. Journal of Animal Science. 68(1): 853-862.

Richards, M. \& Proszkowiec-Weglraz, M. 2007. Mechanisms regulating Feed Intake, Energy Expenditure, and Body Weight in Poultry. Poultry Science. 86(1): 1487-1490.

Roche, J. 2006. The effect of nutritional management of the dairy cow on reproductive efficiency. Animal Reproduction Science. 96(1): 282-296. doi:10,1016/j. anireprosci,2006,08,007.

Roche, J., Friggens, N., Kay, J., Fisher, M., Stafford, K. \& Berry, D. 2009. Invited review: Body condition score and its association with dairy cow productivity, health, and welfare. Journal of Dairy Sience. 92(12): 5769-5801. doi:10,3168/jds,2009-2431.

Romero, J., Rojas, J. \& Estrada, S. 2011. El programa VAMPP Bovino, una herramienta para la toma de decisiones. Ventana Lechera. 16: 4-10. 
Saborío, A. \& Sánchez, J. 2013. Prevalencia y factores de riesgo relacionados con la cetosis clínica y subclínica tipo I y II en un hato de vacas Jersey en Costa Rica. Agronomía Costarricense. 37(2): 17-19.

Samková, E., Špička, J., Pešek, M., Pelikánová, T. \& Hanuš, O. 2012. Review Animal factors affecting fatty acid composition of cow milk fat: A review. South African Journal of Animal Science. 42(2): 83-100.

Scandolo, D. 2007. Desbalance energía/proteína en la dieta. Revista del Colegio de Médicos Veterinarios de la provincia de Santa Fe. 25(181): 22-23.

Sheahan, J. \& Kay, J. 2013. Carbohydrate supplements and their effects on pasture dry matter intake, feeding behavior, and blood factors associated with intake regulation. Journal of Dairy Science. 96(12): 7818-7829. doi: 10,3168/jds,2013-6981.

Spek, J., Bannink, A., Gort, G., Hendriks, W. \& Dijkstra, J. 2013. Interaction between dietary content of protein and sodium chloride on milk urea concentration, urinary urea excretion, renal recycling of urea, and urea transfer to the gastrointestinal tract in dairy cows. Journal of Dairy Science. 96(9): 5734-5745. doi:10,3168/jds,2013-6842.

Spek, J., Gort, G., Hendriks, W. \& Dijkstra, J. 2012. Effect of sodium chloride intake on urine volume, urinary urea excretion, and milk urea concentration in lactating dairy cattle. Journal of Dairy Science. 95(12): 7288-7298. doi: 10,3168/jds,2012-5688.

Stahel, P., Purdie, N. \& Cant, J. 2014. Use of dietary feather meal to induce histidine deficiency or imbalance in dairy cows and effects on milk composition. Journal of Dairy Science. 97(1): 439-445. doi:10,3168/jds, 2013-7269.

Stoop, W., Bovenhuis, H., Heck, J. \& van Arendonk, J. 2009. Effect of lactation stage and energy status on milk fat composition of Holstein-Friesian cows. Journal of dairy science. 92(4): 1469-1478. doi:10,3168/jds,2008-1468.

Thorup, V., Edwards, D. \& Friggens, N. 2012. On-farm estimation of energy balance in dairy cows using only frequent body weight measurements and body condition score. Journal of Dairy Science 95(4): 1784-1793. doi:10,3168/jds,2011-4631.

Van Knegsel, A., Remmelink, G., Jorjong, S., Fievez, V. \& Kemp, B. 2014. Effect of dry period length and dietary energy source on energy balance, milk yield, and milk composition of dairy cows. Journal of Dairy Science. 97(3): 1499-1512. doi:10,3168/jds,2013-7391.

Van Lier, E. \& Regueiro, M. 2008. Digestión en retículo-rumen. Universidad de la República. Montevideo, Uruguay.

Van Knegsel, A., Van den Brand, H., Dijkstra, J., Tamminga, S. \& Kemp, B. 2005. Effect of dietary energy source on energy balance, production, metabolic disorders and reproduction in lactating dairy cattle. Reproduction Nutrition Development. 45(1): 665-688. doi:10,1051/rnd.

Van Soest, P. \& Wine, H. 1967. Use of detergents in the analysis of fibrous feeds IV. Journal of Associated Officials of Agricultural Chemistry. 50(1): 50-55. 
Van Straten, M., Shpigel, N. \& Friger, M. 2009. Associations among patterns in daily body weight, body condition scoring, and reproductive performance in high-producing dairy cows. Journal of Dairy Science. 92: 4375-4385. doi:10,3168/jds,2008-1956.

Vibart, R., Washburn, S., Green, J., Benson, G., Williams, C., Pacheco, D. \& Lopez-Villalobos, N. 2012. Effects of feeding strategy on milk production, reproduction, pasture utilization, and economics of autumn-calving dairy cows in eastern North Carolina. Journal of Dairy Science. 95(2): 997-1010. doi:10,3168/jds,2011-4755.

Wattiaux, M. \& Howard, W. 2000. Alimentos para Vacas lecheras. Instituto Babcock para la investigación y desarrollo internacional de la Industria Lechera. Universidad de Wisconsin. Madison, Wisconsin.

Woodford, S., Murphy, M. \& Davis, C. 1984. Water dynamics of dairy cattle as affected by initiation of lactation and feed intake. Journal of Dairy Science. 67(1): 2336-2346.

Zaaijer, D. \& Noordhuizen, J. 2003. A novel scoring system for monitoring the relationship between nutritional efficiency and fertility in dairy cows. Irish Veterinary Journal. 56: 145-151.

Zebeli, O., Dijkstra, J., Tafaj, M., Steingass, H., Ametaj, B. \& Drochner, W. 2008. Modeling the adequacy of dietary fiber in dairy cows based on the responses of ruminal $\mathrm{pH}$ and milk fat production to composition of the diet. Journal of Dairy Science. 91(5): 2046-2066. doi:10,3168/jds,2007-0572. 